\title{
Effect of bran, ispaghula, and inert plastic particles on gastric emptying and small bowel transit in humans: the role of physical factors
}

\author{
A McIntyre, R M Vincent, A C Perkins, R C Spiller
}

\begin{abstract}
Background-Coarse bran is known to accelerate transit through the whole gut and to increase stool weight. This effect is much reduced by grinding the bran, suggesting that particle size influences gut motor patterns.
\end{abstract}

Aims-To compare the effect of $15 \mathrm{~g}$ coarse bran with $15 \mathrm{~g}$ inert plastic particles and $7 \mathrm{~g}$ of ispaghula on the gastric emptying and small bowel transit of a rice pudding test meal.

Subjects-13 healthy volunteers.

Methods-Transit of ${ }^{99 m}$ Tc labelled rice studied by $\boldsymbol{\gamma}$-scintigraphy measuring gastric emptying and colonic arrival over 10 hours. Small bowel transit was estimated from the difference between time to $\mathbf{5 0} \%$ gastric emptying and $\mathbf{5 0} \%$ colonic arrival.

Results-Bran delayed gastric emptying by 22 (SEM 8) minutes compared with control values of 88 (SEM 6) minutes $\mathbf{p}<0.05$. Ispaghula and plastic particles had no significant effect. Small bowel transit was accelerated compared with control values of 322 (SEM 29) minutes, decreasing by 95 (29) minutes and 62 (22) minutes after bran and plastic particles respectively. Ispaghula again showed no significant effect.

Conclusion-Coarse bran delays gastric emptying and accelerates small bowel transit. The marked acceleration of small bowel transit also seen with inert plastic particles may be due to increased upper gut secretions after stimulation of enteric nerves.

(Gut 1997; 40: 223-227)

Keywords: bran, ispaghula, gastric emptying, small bowel, motility.

Department of

Medicine

A McIntyre

R C Spiller

Department of Medical Physics, University

Hospital, Queen's

Medical Centre,

Nottingham

R M Vincent

A C Perkins

Correspondence to:

Dr R C Spiller

Division of Gastroenterology,

University Hospital,

Nottingham NG7 2UH.

Accepted for publication

6 September 1996 g/day) increase stool weight ${ }^{2-4}$ and reduce whole gut transit times. This laxative effect of bran depends at least in part on its particulate nature, as coarse bran increases stool weight more than fine bran. ${ }^{5}$ Coarse bran results in softer, fragmented stools, which are heavier because of both increased percentage water, increased bacterial mass, and weight of un- digested bran residue. By contrast equal weights of finely divided cellulose or fine ground bran increases stool weight to a similar extent without altering \% water, producing a formed stool with an effect on transit time that is intermediate between control and coarse bran. ${ }^{6}$ The viscous gelling agent ispaghula also increases stool weight ${ }^{78}$ but in humans at least it does not always shorten transit, ${ }^{8}$ perhaps because of the increased viscosity of small bowel contents. This enhanced ability of coarse bran to accelerate transit compared with fibre sources, which increase stool bulk equally, is as yet unexplained. One possibility is that the unfermentable particles of bran stimulate intestinal nerve endings resulting in either mucosal secretion or a more propulsive motor pattern. Recent studies ${ }^{9}$ have suggested that $15 \mathrm{~g}$ inert plastic particles can increase stool water and accelerate transit as much as $37 \mathrm{~g}$ of coarse bran but have not shown from which region of the gut this effect originates. The small bowel, which is well innervated and is known to respond to mechanical stimulation by secreting fluid, ${ }^{10}$ seemed to us to be the most likely site of action. Faster transit here, by reducing nutrient and water absorption, would increase ileocolonic inflow and hence accelerate colonic transit.

The present study therefore aimed to examine the effect of coarse bran on small bowel transit and to compare this with inert plastic particles. We also examined the effect of a contrasting viscous, but non-particulate, pure fibre source ispaghula which, in dogs at least, ${ }^{11}$ increases small bowel water content but does not alter small bowel transit.

\section{Methods}

Thirteen healthy volunteers, eight men and five women, mean age 60 (range 50-72) years, free from gastrointestinal symptoms and taking no regular medication, took part in this four way, randomised, crossover study. Subjects attended after an overnight fast on four occasions and ate a rice pudding test meal with or without either bran, fybogel, or inert plastic particles. Subjects were asked to eat all the meal within five minutes. Gastric emptying, small bowel transit, and colonic filling were measured by $\gamma$-scintigraphy on each occasion. All women were postmenopausal. The study was approved by Nottingham University Medical School ethics committee and the Administration of Radioactive Substances 
Advisory Committee of the Department of Health.

STUDY PROTOCOL

Subjects were requested to avoid alcohol and known cathartics including curries and laxatives for two days before the study. Two subjects smoked occassionally and they avoided smoking on the study day.

Two days before study subjects adhered to a $20 \mathrm{~g}$ fibre diet and avoided alcohol. On each study day they ate one of four ${ }^{99 \mathrm{~m}} \mathrm{Tc}$ labelled rice meals, A, B, C, or D (Table I). We used a modified latin square design to overcome any order effects. After the meal, radioactive markers $\left(0.33 \mathrm{MBq}{ }^{99 \mathrm{~m}} \mathrm{Tc}\right.$ pertechnetate soaked on to filter paper), were taped to the skin, both anteriorly and posteriorly, where the midclavicular line met the right costal margin. Serial anterior and posterior scintigraphic images, each of 30 seconds duration, were then obtained at 20, 40 and 60 minutes, and at 30 minute intervals for the next four hours and then hourly until 10 hours after dosing, when the subjects were allowed home.

\section{FEEDING PATTERN ON STUDY DAY}

Once gastric emptying of the test meal was complete subjects were allowed water ad libitum and were fed a low fibre, $600 \mathrm{kcal}$ sandwich lunch five hours after dosing and 2.5 hours later an afternoon tea consisting of decaffeinated tea with two plain biscuits. Nine and a half hours after dosing they received a $1000 \mathrm{kcal}$ standard meal consisting of chicken casserole with vegetables, and fruit pie and custard.

ADDITIONS TO TEST MEAL

Bran

A total of $15 \mathrm{~g}$ wheat bran (Holland and Barret Health Foods, Hinkley, Leicestershire, UK) was uniformly mixed into the rice pudding. The unprocessed bran, which is crushed to about $1 \mathrm{~mm}$ thickness, had a particle size between $2-5 \mathrm{~mm}$.

Fybogel

A total of $7 \mathrm{~g}$ of Fybogel was used. This contains $3.5 \mathrm{~g}$ husk of the dried seeds of Plantago ovata, $6 \mathrm{mmol} \mathrm{NaHCO}_{3}$, and citric

TABLE I Test meal

Meal A

$325 \mathrm{kcal}$

$220 \mathrm{~g}$ Creamed rice pudding

$25 \mathrm{~g}$ anhydrous rice labelled with $5.0 \mathrm{MBq}^{99 \mathrm{~m}} \mathrm{Tc} /$ tin colloid

10 ml condensed milk

34 g Robinson's seedless raspberry jam

$100 \mathrm{ml}$ concentrated orange juice

Meal $\mathrm{B}=\mathrm{A}+15 \mathrm{~g}$ coarse wheat bran (Holland and Barret

Health Foods, Hinkley, Leicestershire, UK)

Meal C=A+15 g irregular plastic particles (Portex plc, Hythe, Kent, UK).

Meal D=A+7 $\mathrm{g}$ ispaghula (Fybogel, Reckitt and Colman, Hull, UK) acid. The particle size is $<0.2 \mathrm{~mm}$ and the granules rapidly hydrate on contact with the water in the rice pudding to produce a viscous mixture.

\section{Plastic particles}

These were polythene mixed with barium sulphate to yield a specific density of $1 \cdot 3$, kindly made available by Portex plc, Hythe, Kent, UK. They were of irregular shape, mean weight $12 \mathrm{mg}, 1-2 \mathrm{~mm}$ in size; $15 \mathrm{~g}$ were mixed with the rice pudding.

\section{LABELLING}

\section{Rice meal}

Dry short grain pudding rice ( $25 \mathrm{~g}$ ) was heated with $50 \mathrm{ml}$ water and ${ }^{99 \mathrm{~m}}$ Tc-tin colloid solution. This was slowly cooked until all the liquid was absorbed but the rice remained intact. The rice meal was then labelled by mixing the $25 \mathrm{~g}$ labelled rice into the rice pudding. The amount of rice added to each meal was adjusted to provide $5 \mathrm{MBq}{ }^{99 \mathrm{~m}} \mathrm{Tc}$. We have previously shown the stability of the ${ }^{99 \mathrm{~m}} \mathrm{Tc}$ binding using a similar method, with 78 $(82-68) \%$ of the label remaining bound to the rice at three hours when incubated in simulated gastric juice. ${ }^{12}$ The total absorbed dose of ionising radiation amounted to $<0.50 \mathrm{mSv}$. Previous studies using a similar meal had indicated that the bran and ${ }^{99 \mathrm{~m}} \mathrm{Tc}$ label do not separate significantly during their passage to the colon. ${ }^{12}$

ANALYSIS OF SCINTISCANS

The radioactive markers over the hepatic region were used to align the serial gammacamera images. The ${ }^{99 \mathrm{~m}} \mathrm{Tc}$ label provided clear images of stomach and after some hours the ascending colon. A region of interest program was used to obtain total gastric, fundal, and colonic count rates. The whole series of images was reviewed in each case before outlining the stomach and colon. The gastric outline was divided into the fundus and antrum by drawing a line bisecting the gastric image at the incisura. Geometric mean counts were calculated for each region from anterior and posterior counts corrected for background and radioactive decay. Regional time-activity curves could then be constructed. Gastric emptying was assessed from time to $50 \%$ emptying of the whole stomach $\left(\mathrm{T}_{50} \mathrm{GE}\right)$ as well as from the fundus ( $T_{50}$ fundus). The head of the meal label did not reach the transverse colon before gastric emptying was virtually complete so overlap of the gastric and colonic regions was not a problem. The distribution of isotope was assessed by the geometric centre method measuring counts in the following regions. Region 1 was defined as the terminal ileum where isotope collected before spreading out into the ascending colon. The colonic regions were obtained from the colonic image by bisecting the hepatic and splenic flexures, which defined the ascending colon, the 
transverse colon, and the descending colon. Regions 2 and 3 were the lower and upper halves of the ascending colon, regions 4 and 5 the right and left halves of the transverse colon, and region 6 the descending colon. The seventh region was the rectosigmoid region. Excreted isotope assessed from the fall in total counts after defecation was allocated to the region 8. From the sum of the number of counts in region $\mathbf{n} \times \mathbf{n}$ divided by the total colonic counts, a geometric centre could be calculated. The geometric centre was therefore a number from 1 to 8 giving a measure of progress of the isotope bolus along the colon. ${ }^{1314}$ Mouth-caecum transit was assessed from time to $50 \%$ colonic filling (M-CTT) and small bowel transit was then calculated from the difference $M-C T T$ minus $T_{50}$ GE. Overall progression of the isotope through the proximal colon was assessed from the geometric centre at the end of the study.

\section{STATISTICS}

Results are expressed as means (SEM). As the results approximated to a normal distribution the overall significance of treatment effects were assessed using analysis of variance ANOVA and then individual comparisons by paired $t$ test.

\section{Results}

All test meals were eaten without difficulty within the five minutes as requested, although the bran and ispaghula made the meal distinctly more viscous and the bran required more chewing.

Gastric emptying of the whole stomach $\left(T_{50}\right.$ GE), was significantly delayed by the presence of bran although not by ispaghula (Fig 1 and Table II). The small difference between the control meal and that with plastic particles was not significant $(p=0 \cdot 1)$. The delay with bran occurred without any significant difference in emptying of the fundus suggesting that the delay was due to accumulation of meal in the antrum.

More striking was the finding that colonic arrival of $50 \%$ of the bran meal label occurred 74 (24) minutes earlier than with the control meal $(p<0.02, n=13$; Table II), despite the

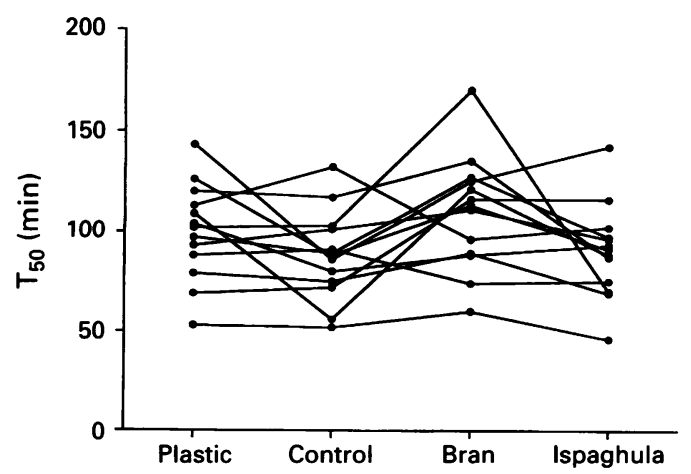

Figure 1: Effect of bran, plastic particles, and ispaghula on gastric emptying. Bran significantly delayed emptying compared with control $(p<0.05, n=13)$, whereas neither plastic particles nor ispaghula did.
TABLE II Regional transit data (min)

\begin{tabular}{lcllc}
\hline & Control & Bran & Plastic & Ispaghula \\
\hline Gastric $\mathrm{T}_{50} \mathrm{GE}$ & $88(6)$ & $110(8)^{\star}$ & $100(7)$ & $90(7)$ \\
Fundus T $_{50}$ & $50(8)$ & $52(9)$ & $51(11)$ & $55(6)$ \\
Colon filling $_{50}$ & $410(29)$ & $337(15) \dagger$ & $359(32)^{\star}$ & $388(25)$ \\
Small bowel $_{50}$ & $322(29)$ & $227(15)^{\star \star}$ & $260(29) \dagger$ & $298(21)$ \\
\hline
\end{tabular}

Values are means (SEM).

${ }^{\star} \mathrm{p}<0.05 ; \mathrm{tp}<0.02 ;{ }^{\star \star} \mathrm{p}<0.01 v$ control.

delayed gastric emptying. Likewise the plastic particles showed a similar acceleration of 51 (21) minutes, $(\mathrm{p}<0.05, \mathrm{n}=13)$ while ispaghula showed no such effect (Table II).

The net effect of the delayed gastric emptying and accelerated colonic arrival was a striking acceleration of small bowel transit, which fell by 95 (29) minutes from a control value of 322 (29) to 227 (15) minutes with bran, $\mathrm{p}<0.01, \mathrm{n}=13$ ). Plastic particles showed a similar although lesser effect with a fall of 62 (22) minutes $\mathrm{p}<0.02$ ) whereas ispaghula again showed no significant change with a fall of 15 (17) minutes (NS) (Fig 2 and Table II).

Overall progression through the colon, as assessed by the geometric centre at the end of the study, showed a tendency to greater progression after the bran meal, the geometric centre at 10 hours being $3.0(0 \cdot 1)$ compared with a control value of $2.8(0.2)$ but this did not reach significance $(p=0 \cdot 2)$. Likewise there was no difference from control values in the final geometric centre with either ispaghula $(3 \cdot 0(0 \cdot 2))$ or plastic particles $(2 \cdot 8(0 \cdot 2))$.

\section{Discussion}

This study shows the widespread changes in gut motility and function induced by coarse bran. Bran is not only a source of nonabsorbable polysaccharide for colonic fermentation but also when added to any meal alters the physical characteristics, particularly the particle size and viscosity. Although we did not formally assess this, it was obvious that the rice with added bran was much thicker and required more chewing. The finding of delayed gastric emptying confirms our previous studies $^{12}$ showing that coarse bran delayed emptying, whereas fine bran had a much diminished effect. Viscous material traps water

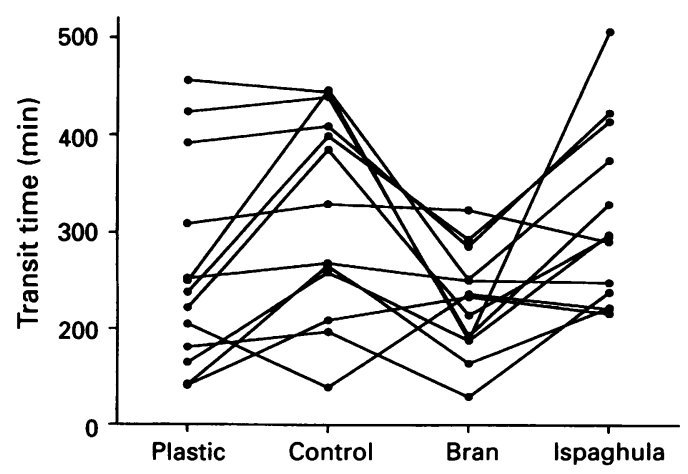

Figure 2: Effect of bran, plastic particles, and ispaghula on small bowel transit time, which is shown in minutes on the vertical axis. Both bran and plastic particles significantly accelerated small bowel transit $(p<0.01$ and 0.02 respectively), whereas ispaghula had no significant difference effect. 
and hinders transpyloric flow, delaying gastric emptying. ${ }^{15-17}$ It is likely that such materials require hydration to reduce their viscosity below a critical level before gastric emptying can ocurr. Earlier studies comparing wholemeal bread and white bread suggested that the bran component of flour delayed emptying of solids. ${ }^{18}$ Our plastic particles did make the meal somewhat thicker but this effect was not apparently sufficient to alter gastric emptying. Ispaghula is a gelling agent which also increases viscosity but this effect is very concentration dependent. Our findings lead us to speculate that after dilution with both endogenous secretions and the orange juice the increase in viscosity was insufficient to exert any noticeable effect.

Our most striking finding was the pronounced acceleration of small bowel transit by both bran and plastic particles, probably a reflection of increased luminal fluid. This would be predicted to increase ileocolonic inflow and to accelerate transit through the ascending colon which others have found to correlate with increased stool volumes. ${ }^{19}$ Although we found a tendency for bran to accelerate the progression of isotope through the colon in this study this was not significant 10 hours after the dose. However, in a subsequent study ${ }^{20}$ we found isotope to be significantly further advanced along the colon with coarse bran, but this difference was only significant at 11 hours after the dose, implying that the effect requires some time to develop. The present study showed a much larger effect on the small bowel transit than our previous report ${ }^{12}$ despite using an identical test meal and bran dose. One difference, which may be important, is the further meals at five, 7.5 , and 9.5 hours, which were not given in the earlier study. Eating increases ileal flow after three to four hours and this accelerates transfer from distal ileum to colon. ${ }^{21}$ This may account for the faster small bowel transit in the control arm of the present study, which was 36 minutes less than in the previously reported fasting study. Bran seems to enhance the effect of eating as the difference in small bowel transit was even greater, at 95 minutes, when bran was added to the meal.

Although the numbers were small and their methods different, the earlier study by Jenkins et $a l^{22}$ supports our findings in also showing that with a glucose meal bran accelerated small bowel transit but in their study, by contrast with ours, gelling agents such as $12 \mathrm{~g}$ pectin, guar, and gum traganth all delayed transit. Just why bran behaves differently from other fibre sources is uncertain but the jejunum can distinguish and react with different motor patterns to bran, cellulose and guar as previously shown in dogs. ${ }^{11}$ Bran added to a test meal did not alter flow rates but did induce a pattern of clustered contractions of higher amplitude which were associated with a rapid transit when compared with the control meal. By contrast, guar resulted in more continuous but lower amplitude contractions and was associated with a marked increase in flow but no acceleration of transit. Both guar and cellulose caused a much larger increase in small bowel contents than bran and yet were associated with delayed rather than rapid transit, perhaps related to increased luminal viscosity. Thus mere distension of the gut is insufficient to accelerate transit, which must depend on more specific factors such as chemical composition or perhaps physical factors such as particle size and texture.

The fact that in our study inert plastic particles exerted a similar accelerating effect to bran on the small intestine, likewise strongly suggests that neither water trapping and resulting luminal distension nor chemical stimulation is an adequate explanation for the effect of bran. The small bowel is profusely innervated with sensory nerves which may be mechanically stimulated by the chemically inert particles. The response may include secretion $^{10}$ or propulsive motor patterns. Previous dog and pig studies have also shown that indigestible particles accelerate whole gut transit ${ }^{23}$ suggesting that this effect is not unique to humans.

One other possible mechanism relates to the increased flow through the upper small bowel, which has been reported in pigs given high fibre compared with refined test meals. ${ }^{24}$ At least part of this is due to increased pancreatic secretions. These, like all upper gastrointestinal secretions, have a substantial cephalic component driven by the act of chewing, which is much increased in bran based foods. ${ }^{25}$ Accelerated transit with bran may therefore be due to an increase in flow combined with relatively low viscosity once diluted.

Our dose of ispaghula of $7 \mathrm{~g}$ (two sachets) was based on high normal clinical dosage. It is possible than using a higher dose would have elicited a more marked response but certainly at a dose which significantly increases stool weight $^{8}$ we did not see alteration in small bowel transit, implying that this is not an important part of its effect.

Accelerated small bowel transit is a common feature of vegetarians and some patients with otherwise unexplained diarrhoea. Our study suggests that as well as chemical composition, the physical form of food should also be taken into account when attempting to explain the differing small bowel transit associated with different diets.

We thank Dr M Frier, principal radiopharmacist, for his advice concerning the radiolabelling.

1 Heaton KW. Dietary fibre after 21 years of study the verdict remains one of fruition and frustration. $B M F$ F 1990; 300: 1479-80.

2 Burkitt DP, Walker ARP, Painter NS. Effect of dietary fibre on stools and transit-times, and its role in the causation on stools and transit-times, and its
of disease. Lancet 1972; 2: 1408-11.

3 Cummings JH, Hill MJ, Jenkins DJA, Pearson JR, Wiggins HS. Changes in fecal composition and colonic function due to cereal fiber. Am F Clin Nutr 1976; 29: function

4 Cummings $\mathrm{JH}$. Constipation, dietary fibre and the control of large bowel function. Postgrad Med $\mathcal{F} 1984 ; 60$ : 811-9. 5 Brodribb AJM, Groves C. Effect of bran particle size on stool weight. Gut 1979; 19: 60-3.

6 Wrick KL, Robertson JB, Van Soest PJ, et al. The influence of dietary fiber source on human intestinal transit and stool output. F Nutr 1983; 113: 1464-79.

7 Prior A, Whorwell PJ. Double blind study of ispaghula in irritable bowel syndrome. Gut 1987; 28: 1510-3.

8 Eastwood MA, Smith AN, Brydon WG, Pritchard J. Comparison of bran, ispaghula, and lactulose on colon function in diverticular disease. Gut 1978; 19: 1144-7. 
9 Tomlin J, Read NW. Laxative properties of indigestible plastic particles. BM7 1988; 297: 1175-6.

10 Beubler E, Juan H. PGE-released blood flow and transmucosal water movement after mechanical stimulation of the rat jejunal mucosa. Naunyn Schmeiderberg's Arch the rat jejunal mucosa.

11 Bueno L, Praddaude F, Fioramonti J, Ruckebusch Y. Effect of dietary fiber on gastrointestinal motility and jejuna transit time in dogs. Gastroenterology 1981; 80: 701-7.

12 Vincent R, Roberts A, Frier M, Perkins AC, MacDonald IA Spiller RC. Effect of bran particle size on gastric emptying and small bowel transit in humans: a scintigraphic study. Gut 1995; 37: 216-9.

13 Krevsky B, Malmud LS, D'Ercole F, Maurer AH, Fisher RS. Colonic transit scintigraphy: A physiologic approach to the quantitative measurement of colonic transit in humans. Gastroenterology 1986; 91: 1102-12.

14 Barrow L, Steed KP, Spiller RC, et al. Quantitative, noninvasive assessment of antidiarrhoeal actions of codeine using an experimental model of diarrhea in man. Dig Dis using an experimental mod

15 Meyer JH, Elashoff GJ, Reedy T, Dressman J, Amidon G Effects of viscosity and fluid outflow on postcibal gastric emptying of solids. Am $\mathcal{F}$ Physiol 1986; 250: G161-4.

16 Prove J, Ehrlein $\mathrm{H}$. Motor function of gastric antrum and pylorus for evacuation of low and high viscosity meals in dogs. Gut 1982; 23: 150-6.

17 Tomlin J, Brown N, Ellis A, Carlsson A, Bogentoft C Read W. The effect of liquid fibre on gastric emptying in the rat and humans and the distribution of small intestinal contents in the rat. Gut 1993; 34: 1177-81.

18 Grimes DS, Goddard J. Gastric emptying of wholemeal and white bread. Gut 1977; 18: 725-9.

19 Vassallo M, Camilleri M, Phillips SF, Brown ML Chapman NJ, Thomforde GM. Transit through the proximal colon influences stool weight in the irritable bowel syndrome. Gastroenterology 1992; 102: 102-8.

20 Hebden JM, Blackshaw PE, Spiller RC, et al. Effect of bran on colonic targeting of a novel drug delivery system. Gastroenterology 1995; 108: A612.

21 Spiller RC, Brown ML, Phillips SF, Azpiroz F. Scintigraphic measurements of canine ileocolonic transit. Direct and indirect effects of eating. Gastroenterology 1986; 91: 1213-20.

22 Jenkins DJA, Wolever TMS, Leeds AR, et al. Dietary fibres, fibre analogues, and glucose tolerance: importance of rore analogues, and glucose to

23 Cherbut C, Ruckebusch Y. The effect of indigestible particles on digestive transit time and colonic motility in dogs and pigs. Br $\mathcal{F}$ Nutr 1985; 53: 549-57.

24 Johansen HN, Bach Knudsen KE. Effects of wheat-flour and oat mill fractions on jejunal flow, starch degradation and absorption of glucose over an isolated loop of jejunum in pigs. Brit $\mathcal{F}$ Nutr 1994; 72: 299-313.

25 Zebrowska $T$, Low AG, Zebrowska $H$. Studies on gastric digestion of protein and carbohydrate, gastric secretion and exocrine pancreatic secretion in the growing pig. $\mathrm{Br}$ 